\title{
Comparative evaluation of radiometers in the emission of energy density issued by different modes of photoativation
}

\author{
Diogo de Azevedo Miranda ${ }^{1 *}$, Filipe Assimos Silva Oliveira ${ }^{2}$, Matheus Pereira Bolotari² and Yara Machado Pereira $^{2}$ \\ ${ }^{1}$ Professor Dr. of the Hospital and Maternity Therezinha de Jesus (HMTJ) - Faculty of Medical Sciences and Health of Juiz de Fora / SUPREMA - Departament \\ of Dentistry, Brazil \\ ${ }^{2}$ Student, Dental of Faculty of Medical Sciences and Health of Juiz De Fora, Department of Dentistry, Brazil
}

\begin{abstract}
Introduction: In order to ensure a better polymerization of resinous materials and a success in the dental clinic, the light-curing devices are becoming increasingly included in the day-to-day clinical practices. As efficacy of the restorations, light-curing devices depend on the density of energy, the radiometers are instruments used to measure this irradiance, depending on the mode chosen to carry out the photoactivation process.
\end{abstract}

Objective: Comparative evaluation of two radiometers (Ecel and Sdi) in the emission of energy density emitted by two methods of photoactivation: high and soft start.

Method: 10 Bluephase photopolymerizers were tested in High and Soft-Start modes and two radiometer devices used to verify the irradiance emitted in the two photoactivation modes. All the devices were tested by reading consecutively 3 times and then $\mathrm{b}=$ averaged energy density for each radiometer and mode.

Results: The statistical analysis of the data indicated that there was a significant difference between the variances of the two radiometers and the two photoactivation modes of the light curing device Bluephase.

Conclusion: The Ecel RD-7 radiometer with rechargeable battery presented better results than the SDI radiometer. And independent of the radiometer in use, the high-light mode has a high result in the Soft-Start mode.

\section{Introduction}

Currently, the influence of photopolymerization on the final properties of restorative materials is of utmost importance. Studies show that the final properties of a composite photopolymerizable resin depends mainly on the amount of energy supplied during irradiation in which radiometers, apparatus that measure the concentration of light emitted at various scales or their intensity at a wavelength, is used $[1,2]$.

The use of photopolymerizing devices used by dental surgeons with adequate power acts on the success of such restorations, since the inverse action of this procedure generates failure, leading to superficial spots, marginal infiltration and also monomers [3]. The mechanism of the photopolymerization process is related to camphorquinone which is denoted as a photoinitiator often found in most photopolymerizable restorative materials. When exposed to light, in the presence of initiators such as amines, the formation of free radicals occurs, in which the polymerization process begins by the conversion of monomers into polymers [3,4].

The dental restorations depend on successful photoactivation, from a suitable polymerization. It should have a minimum irradiance of approximately $400 \mathrm{~mW} / \mathrm{cm}^{2}$, with a time of $40 \mathrm{~s}$ in $2 \mathrm{~mm}$ increments, generating a density of $16 \mathrm{~J}[5,6]$. A minimum value of $300 \mathrm{~mW} / \mathrm{cm}^{2}$ is acceptable provided there is an additional polymerization time. Inappropriate photoactivation of resin-based materials leads to lower conversion rates [3-5].

According to work done by Heo, et al. (2013) [7], physics defines energy density as the product of the light intensity of the photopolymerizer used and the photo-activation time. Already light intensity $\left(\mathrm{mW} / \mathrm{cm}^{2}\right)$ is the collective measure of the incidence of photons, together related to the number and wavelength of photons and the area in which the incident light is irradiated. For photoactivation time, it is understood that it is the duration of the photon supply during the polymerization process. However, the energy density, light intensity and the photoactivation time may be different.

The total amount of energy per unit area, the so-called energy density (ED) is the product of power per unit area (power density: PD) for the duration of irradiation (cure time). For a given ED, different combinations of PD and curing time can be used to cure composite materials. High light intensity with short photoactivation may be beneficial in reducing treatment time, but may cause incomplete polymerization, poor physical properties and high temperature caused by the photon blast for a short period of time during the onset of the photoinitiation stage. Low intensity with long cure time may reduce polymerization shrinkage, but inevitably causes discomfort to patients by increasing the duration of treatment [5].

*Correspondence to: Diogo de Azevedo Miranda, Rua Sampaio 330/602, Granbery, Juiz de Fora, Minas Gerais 36010-360, Brazil, E-mail: diogoodonto@ yahoo.com.br

Key words: photopolymerization, light, irradiation

Received: October 31, 2018; Accepted: November 15, 2018; Published: November 19, 2018 
In view of the importance of periodic maintenance, both on the part of the components and the cleanliness and intensity of the light, since the use and frequency are responsible for the wear of the appliance. It is up to the Dental Surgeon in these cases to have sufficient knowledge about the perfect functioning of the apparatus to request the technical services periodically or whenever necessary as well as the proper maintenance, since this device is part of the day-to-day dental clinics both from colleges and from private and public practices [6-8]. Thus, the objective of this in vitro study was the comparative evaluation of two radiometers in the emission of the energy density emitted by two methods of photoactivation: high and soft start.

\section{Methods}

\section{Experimental design}

The present study was of experimental quantitative character, whose non-probabilistic sample was composed by the light-curing apparatus of the Bluephase brand at one level $(n=10)$. The factors under study were radiometers (at two levels) and photoactivation methods at two levels (soft and High) and the response variable was the irradiance (enerfgi density).

The criterion of inclusion for the work was apparatus in good condition, periodic maintenance, adequate power, high intensity of light and charged batteries. Appliances in poor condition, without periodic maintenance, with inadequate power, low light intensity and with discharged batteries were excluded.

\section{Reading of apparatus irradiance}

To read the irradiance, the ECEL RD-7 and SDI radiometers were used, in which they were calibrated every 4 readings. Then each Bluephase light curing unit was fired for 20 seconds in direct contact with the radiometer sensor. The irradiance of the photopolymerizer was evaluated in the Soft-start and High modes.

In a first reading the activation of the Soft-start mode and in a second reading, the high mode irradiance were performed. To carry out the reading, the light-curing tips of each mode were placed directly on the sensitive area of the ECEL RD-7 and SDI radiometers with flashing light for 20 seconds. Afterwards, the observed results were emitted with the irradiance value for each mode of photoactivation.

\section{Results}

\section{Statistical analysis}

Initially, exploratory analyzes were performed and as the data met the assumptions of a parametric analysis, variance analysis (ANOVA) was used, taking into account in the statistical model that the study factors were analyzed in the same apparatuses. The analyzes were performed in the $\mathrm{R}^{\star}$ program, with a significance level of $5 \%$.

${ }^{*} \mathrm{R}$ Core Team (2017). A: A language and environment for statistical computing. R Foundation for Statistical Computing, Vienna, Austria. URL https://www.R-project.org/.

\section{Irradiance}

It can be observed in Table 1 and Figure 1 that, regardless of the mode of photoactivation, the Ecel radiometer presented significantly higher mean irradiance than SDI $(\mathrm{p}<0.05)$. It is also noted that,
Table 1. Mean (standard deviation) of the irradiance (energy density) as a function of the photoactivation mode and the radiometer

\begin{tabular}{|c|c|c|c|}
\hline \multirow{2}{*}{ Radiometer } & \multicolumn{2}{|c|}{ Photoactivation mode } & \multirow{2}{*}{} \\
\cline { 2 - 4 } & High & Soft start & \multirow{2}{*}{} \\
\hline SDI & $1200,70(112,56)$ & $1127,00(93,45)$ & b \\
\hline Ecel & $1436,60(169,18)$ & $1336,60(143,57)$ & a \\
\hline & A & B & \\
\hline
\end{tabular}

Distinguished letters (upper and lower case) indicate significant differences $(\mathrm{p} \leq 0.05)$. $\mathrm{p}$ $($ radiometer $)<0.0001 ; \mathrm{p}($ photoactivation $)=0.0017 ; \mathrm{p}($ tip $\times$ photo-activation $)=0.6021$

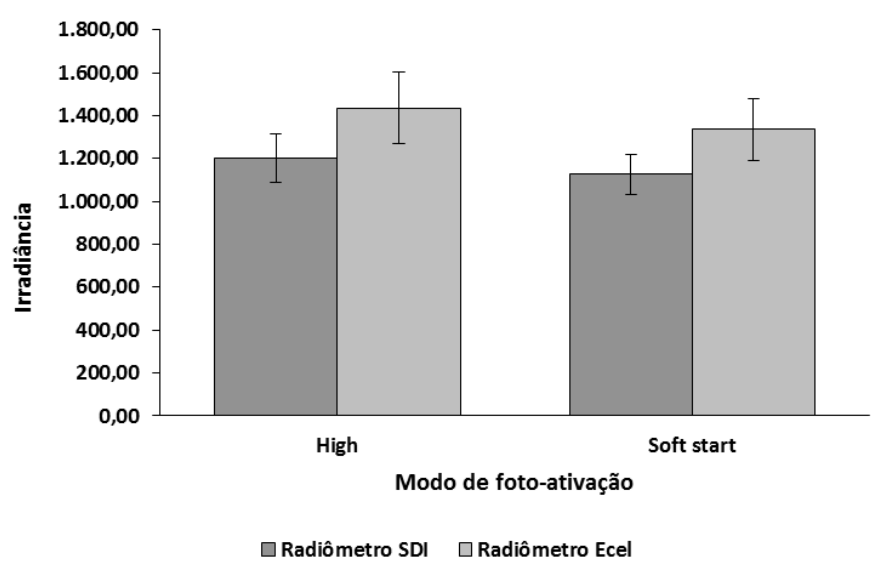

Figure 1. Mean (standard deviation) of the irradiance as a function of the photoactivation mode and the tip

independently of the radiometer, the high photoactivation mode presented a significantly higher average than the soft start $(\mathrm{p}<0.05)$.

\section{Discussion}

The results of this study showed that, irrespective of the mode of photoactivation, the Ecel RD-7 radiometer had significantly higher mean irradiance than the universal SDI device $(\mathrm{p}<0.05)$. Miranda, et al. [9] compared these devices to the measurement of the irradiance of photopolymerizers and concluded that the Ecel RD-7 radiometer needs a $9 \mathrm{~V}$ rechargeable bacterium while the universal apparatus works with a replaceable lithium-based bacterium that loses its potency as if testing is done. It is important to note that the life-span of a replaceable battery is approximately 1200 photopolymerizations with a duration of 10 seconds each, and may resemble a clock battery [7].

Another result found in this study was that, irrespective of the radiometer, the "High" photoactivation mode showed higher irradiance values than the "soft-Start" method ( $\mathrm{p}<0.05)$. This result is quite consistent with that of other studies and, although it is a laboratory test comparing the quality of tested devices and methods, it can be said that with the values obtained it can be shown that it could induce the professional to use a shorter time of phonotavation, since enough for a resin to achieve an energy density of $16 \mathrm{~J}\left(800 \mathrm{~mW} / \mathrm{cm}^{2} \mathrm{X} 20\right.$ seconds of polymerization) [3].

Taking these results into account with clinical practice, some studies have used different photoactivation approaches such as: low intensity in continuous light, high intensity in continuous light, photo-activation in steps and high intensity in continuous light $[8,9]$.

Although this study has not been used to test the effect of methods on the physical and mechanical properties of resinous materials, it is worth noting that the Soft-Start method allows a longer flow time of the monomers besides promoting a better marginal adaptation of the restoration by relaxation of the tensions adhered in the initial 
polymerization phase of the resinous material [5]. The high method uses high intensity in continuous light, uniformly transforming monomers into polymers, creating more resistant polymer chains [10-12].

Thus, it is more common to find numerical results of the High method that are actually larger than the Soft method $[13,14]$ but when evaluating clinical effectiveness the results are contradictory $[15,16]$.

\section{Conclusion} that:

Considering the results obtained in this present study, we conclude

- The Ecel RD-7 radiometer was more effective than the universal radiometer.

- The high photoactivation method showed higher irradiance means than the Soft-Start method.

\section{References}

1. Dewaele M, Asmussen E, Peutzfeldt A, Munksgaard EC, Benetti AR, et al. (2009) Influence of curing protocol on selected properties of light-curing polymers: degree of conversion, volume contraction, elastic modulus, and glass transition temperature. Dent Mater 25: 1576-1584.

2. Ribeiro RAO, Lima FFC, Lima IM, Nascimento ABL, Teixeira HM (2016) Avaliação da intensidade de luz e da manutenção dos aparelhos fotopolimerizadores utilizados em clínicas odontológicas da cidade do Recife-PE. Rev Odontol UNESP 45: 351-355.

3. Miranda DA, Catelan A (2018) Living polymerization techniques and their utility in material synthesis. Ann Clin Case Rep 3: 1494.

4. Marson FC, Mattos R, Sensi LG (2010) Avaliação das condições de uso dos fotopolimerizadores. Revista Dentística On-Line 9: 15-20.

5. Alonso RC, LG Wedge, GM Run, Cunha Brandt W, Run-Nephew L, et al. (2006) Relationship between bond strength and marginal and internal adaptation of composite restorations photocured by different methods. Acta Odontol Scand 64: 306-13.
6. Shimokawa CA, Harlow JE, Turbino ML, Price RB (2016) Ability of four dental radiometers to measure the light output from nine curing lights. $J$ Dent 54: 48-55. [Crossref]

7. Heo YJ, Lee GH, Park JK, Ro JH, García-Godoy F, et al. (2013) Effect of energy density on low-shrinkage composite resins: diode-pumped solid state laser versus quartz-tungsten-halogen light-curing unit. Photomed Laser Surg 31: 28-35. [Crossref]

8. Borges FMGS, Rordigues CC, Freitas SAA, Costa JF, Bauer J (2011) Avaliação da intensidade de luz dos fotoativadores utilizados no curso de Odontologia da Universidade Federal do Maranhão. Rev Ciênc Saúde 13: 26-30.

9. Miranda DA, Souza AS, Souza ML, Costa PBR (2018) Comparison of two radiometers in the validation of the irradiance emitted in the light curing apparatus of the Faculty of Medical Sciences and Health of Juiz De Fora /SUPREMA. Internacional Jpurnal of Innovation Research in medical Science 3.

10. Baratieri LN, Monteiro SJ (2012) Odontologia Restauradora: Fundamentos \& Técnicas. São Paulo: Santos.

11. Santos MJMC, Silva e Souza JR MH, Mondelli RFL (2002) Novos conceitos relacionados à fotopolimerização das resinas compostas. JBD 1: 14-21.

12. Cunha LG, Alonso RC, Correr GM, Brandt WC, Correr-Sobrinho L, et al. (2008) Effect of different photoactivation methods on the bond strength of composite resin restorations by push-out test. Quintessence Int 39: 243-249. [Crossref]

13. Mehl A, Hickel R, Kunzelmann KH (1997) Physical properties and gap formation of light-cured composites with and without 'softstart-polymerization'. J Dent 25: 321330.

14. Consani S, Pereira SB, Sinhoreti MA, Correr Sobrinho L (2002) Effect of the methods of photoactivation and insertion on the hardness of composite resins. Pesqui Odontol Bras 16: 355-360. [Crossref]

15. de Azevedo Miranda D, Sotto-Maior JA, de Oliveira MF, de Oliveira SL (2018) Evaluation of the Irradiance Emitted by Different Modes of Photoactivation with and without the use of Luminous Tip. J Clin Res Dent 1: 1-4.

16. Miranda DA, Prenassi AQ, Correa GF, Costa JAM (2018) Comparative evaluation of the irradiance emitted by different methods of photopolymerization. Mod App Dent Oral Health 3.

Copyright: (C2018 de Azevedo Miranda D. This is an open-access article distributed under the terms of the Creative Commons Attribution License, which permits unrestricted use, distribution, and reproduction in any medium, provided the original author and source are credited. 